\title{
Photodynamic Reaction of Riboflavin and Deoxyguanosine
}

\author{
JOHN F. ENNEVER AND WILLIAM T. SPECK ${ }^{(19)}$ \\ Rainbow Babies and Childrens Hospital, Case Western Reserve University, Cleveland, Ohio, USA
}

\begin{abstract}
Summary
Previous studies have demonstrated that phototherapy depresses serum riboflavin in jaundiced infants. The potential longterm hazards of this in vivo reaction may be significant in view of the in vitro reaction of riboflavin which modifies intracellular DNA in eukaryotic and prokaryotic cells. Previous investigations have suggested that the DNA-modifying activity of riboflavin results from the generation of singlet oxygen and photooxidation of the guanine moieties of the DNA. In the present study, we demonstrate that singlet oxygen is not involved in the photodynamic reaction of riboflavin and deoxyguanosine.
\end{abstract}

\section{Speculation}

In view of the known relationship between DNA-modifying activity and mutagenesis and carcinogenesis, the photodynamic reaction between riboflavin and deoxyguanosine may have adverse long-term effects on children exposed to phototherapy. A better understanding of the characteristics of this photochemical reaction may permit the development of a phototherapy unit effective in the photoisomerization of bilirubin yet devoid of DNA-modifying activity.

Several investigators have shown that standard phototherapy lamps can photodecompose riboflavin in vitro and that newborn infants may develop riboflavin deficiency during phototherapy ( 1 , $6,10)$. This riboflavin deficiency, presumably due to the in vivo photodecomposition of riboflavin, is exaggerated in breast-fed infants and may be prevented by parenteral or oral administration of riboflavin (2). The potential long-term consequences of riboflavin deficiency and/or vitamin supplementation in newborn infants receiving phototherapy have not been defined.

Studies in our laboratory demonstrated that illumination of DNA in the presence of riboflavin resulted in physical chemical changes in this biopolymer (8). The observed changes were consistent with an altered base moiety in the treated DNA. Additional studies with individual deoxynucleosides revealed that only deoxyguanosine was modified when illuminated in the presence of riboflavin (9). Subsequent investigation with human cells in tissue culture indicated that a brief exposure of such cells to phototherapy in the presence of trace amounts of riboflavin resulted in a decrease in the molecular weight of the cellular DNA (8). Followup studies with antinucleotide antibodies suggested that the decreased molecular weight of DNA isolated from cells illuminated in the presence of trace amounts of riboflavin was a consequence of an alteration in the guanine residues (5).

The purpose of the present study was to further characterize the photochemical reactions of riboflavin and to determine the role, if any, of singlet oxygen in the riboflavin-induced photodegradation of deoxyguanosine.

\section{MATERIALS AND METHODS}

The following chemicals were obtained from the indicated chemical supply houses and, except where indicated, were stan- dard reagent grade and were used without further purification: 2 deoxyguanosine and riboflavin, Sigma Chemical Co. (11); 1-butanol, acetic acid, ammonium hydroxide, toluene, sodium azide, and high purity argon, Fisher Scientific Co. (12); $\mathrm{D}_{2} \mathrm{O}(99.8 \% \mathrm{D})$ and $\left[8-{ }^{3} \mathrm{H}\right]$-deoxyguanosine $(3 \mathrm{Ci} / \mathrm{mmole}), \mathrm{ICN}$ (13); Omnifluor, New England Nuclear (14); rose bengal, BDH (15).

Deoxyguanosine was dissolved in $0.05 \mathrm{M}$ phosphate buffer $(\mathrm{pH}$ 7.0) at a concentration of $1 \mathrm{mg} / \mathrm{ml}$. The photosensitizers, either riboflavin or rose bengal, were added to the deoxyguanosine solution to a final concentration of $1.33 \times 10^{-4} \mathrm{M}(8)$, and the resulting solution was protected from light. Sodium azide was used at a concentration of $5 \mathrm{mM}$ in some experiments as described in "Results." For other experiments, $\mathrm{D}_{2} \mathrm{O}$ replaced $\mathrm{H}_{2} \mathrm{O}$ in the phosphate buffer.

Five $\mathrm{ml} \mathrm{samples} \mathrm{were} \mathrm{placed} \mathrm{in} \mathrm{screw-capped,} \mathrm{plastic} \mathrm{flasks} \mathrm{(16)}$ before illumination. Samples which were illuminated in an anerobic environment were bubbled with argon for 2 min before sealing the flask. The samples were placed under a standard phototherapy unit equipped with a broad-spectrum light source (Dura Test Vita Lite). The phototherapy unit was protected from direct sunlight and air-cooled to maintain the sample at room temperature (approximately $23^{\circ} \mathrm{C}$ ). The distance from the light source to the flask was adjusted to achieve a fluence rate (at 450 $\mathrm{nm})$ of $141 \mu \mathrm{W} / \mathrm{cm}^{2}$. Photometric measurements were made with an IL600A photometer coupled to the IL600 photodensitometer (International Light, Inc.).

After illumination, a portion of the sample was diluted 1:40 with phosphate buffer (final deoxyguanosine concentration was $25 \mu \mathrm{g} / \mathrm{ml}$ ). Reference solutions, identical in composition to the samples except for the lack of deoxyguanosine, were illuminated and diluted in a similar manner. The ultraviolet absorption spectra of the samples were recorded on a Cary 210 dual-beam spectrophotometer.

Ascending chromatography was performed on Whatman No. 1 chromatography paper in the following solvent systems: butanol: water $(86: 14 \mathrm{v} / \mathrm{v})$, butanol:water:concentrated ammonium hydroxide $(86: 14: 1.3 \mathrm{v} / \mathrm{v})$, or butanol:water:acetic acid $(4: 5: 1 \mathrm{v} / \mathrm{v})$. Samples consisted of deoxyguanosine $(1 \mathrm{mg} / \mathrm{ml})$ containing $\left[8-{ }^{3} \mathrm{H}\right]-$ deoxyguanosine $(0.066 \mathrm{mCi} / \mathrm{ml})$ plus either riboflavin or rose bengal at $1.33 \times 10^{-4} \mathrm{M}$. After illumination, aliquots (approximately $20 \mu \mathrm{l}$ ) were spotted on the paper and chromatographed for $4 \mathrm{hr}$. The paper was dried and cut into $0.5 \mathrm{~cm}$ lengths, which were placed in $10 \mathrm{ml}$ of a toluene-based scintillant (Omnifluor). Radioactivity was determined in a Nuclear Chicago liquid scintillation counter.

\section{RESULTS}

Illumination of $2^{\prime}$-deoxyguanosine in the presence of $1.33 \times$ $10^{-4} \mathrm{M}$ riboflavin resulted in a progressive change in the ultraviolet absorption spectrum of this nucleoside (Fig. 1). The predominate spectral changes are loss of the 256 and $270 \mathrm{~nm}$ chromophores. Neither deoxyguanosine illumination alone nor riboflavin and deoxyguanosine incubated in the dark demonstrated any spectral change (Fig. 1). Illumination of riboflavin alone followed by incubation with deoxyguanosine in the dark was without effect on 


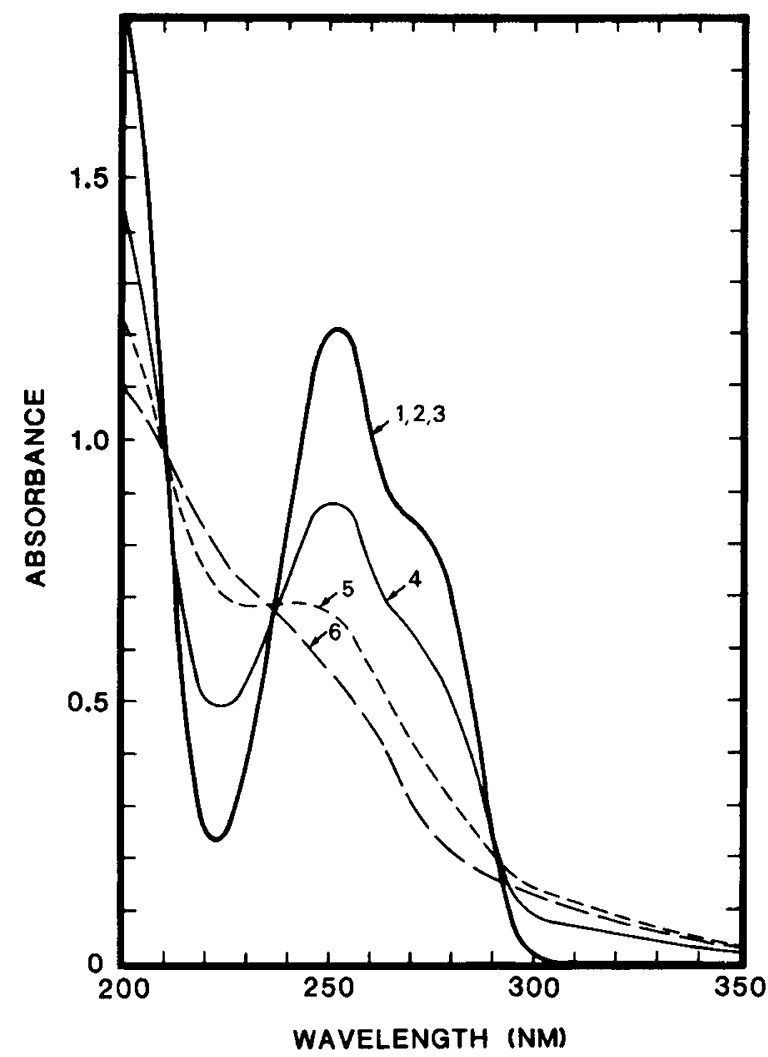

Fig. 1. Effect of illumination in the presence of riboflavin on the absorption spectrum of deoxyguanosine. $l$, untreated deoxyguanosine; 2 , deoxyguanosine illuminated for $2 \mathrm{hr}$ in phosphate buffer; 3 , deoxyguanosine plus riboflavin in the dark; 4 , deoxyguanosine plus riboflavin illuminated for $30 \mathrm{~min}$; 5 , same as 4 illuminated for $60 \mathrm{~min}$; 6 , same as 4 illuminated for $120 \mathrm{~min}$

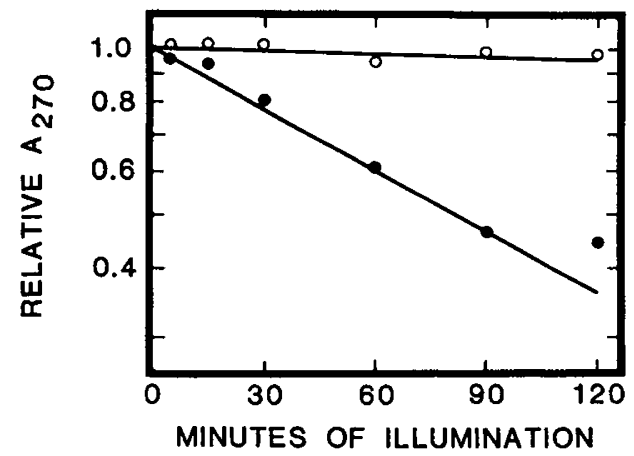

Fig. 2. Comparison of the rates of riboflavin-induced photodecomposition of deoxyguanosine in the presence and absence of oxygen. deoxyguanosine plus riboflavin illuminated in aerobic environment; $O$, deoxyguanosine plus riboflavin illuminated in anerobic environment (argon). Relative $A_{270}$ is the ratio of the absorbance at $270 \mathrm{~nm}$ of the sample to the initial (before illumination) absorbance. The data are plotted on a semilogarithmic scale. The lines are least-squares fit to the data, excluding the 120-min data point for aerobic illumination.

the spectrum of the deoxynucleoside (results not shown). Illumination of deoxyadenosine, deoxycytosine, or thymidine in the presence of riboflavin $\left(1.33 \times 10^{-4} \mathrm{M}\right)$ had no effect on the ultraviolet absorption spectra of these nucleosides (results not shown).

The photodynamic reaction between riboflavin and deoxyguanosine was examined under anaerobic conditions (Fig. 2). These results clearly demonstrated that this photochemical reaction is oxygen dependent. In view of the fact that riboflavin is a known generator of singlet oxygen and that this reactive molecule can photooxidize deoxyguanosine, we examined the role of singlet oxygen in the photodynamic reaction between riboflavin and deoxyguanosine. We initially investigated the reaction between rose bengal, a potent generator of singlet oxygen, and deoxyguanosine (Fig. 3). This reaction demonstrated the characteristics of a singlet oxygen-mediated reaction. More specifically, deuterium oxide, a promoter of singlet oxygen, accelerated the photodecomposition of deoxyguanosine whereas sodium azide, a singlet oxygen scavenger, inhibited the photodecomposition of deoxyguanosine by rose bengal. These properties were not observed with riboflavin and deoxyguanosine (Fig. 4). Although sodium azide inhibited this photochemical reaction, deuterium oxide had no effect on the kinetics of deoxyguanosine photodecomposition.

Additional evidence against a role for singlet oxygen in the photodynamic reaction of riboflavin and deoxyguanosine was obtained by comparing chromatographically the photoproducts of this interaction with those obtained when rose bengal photodecomposes deoxyguanosine (Fig. 5). In addition to the data pre-

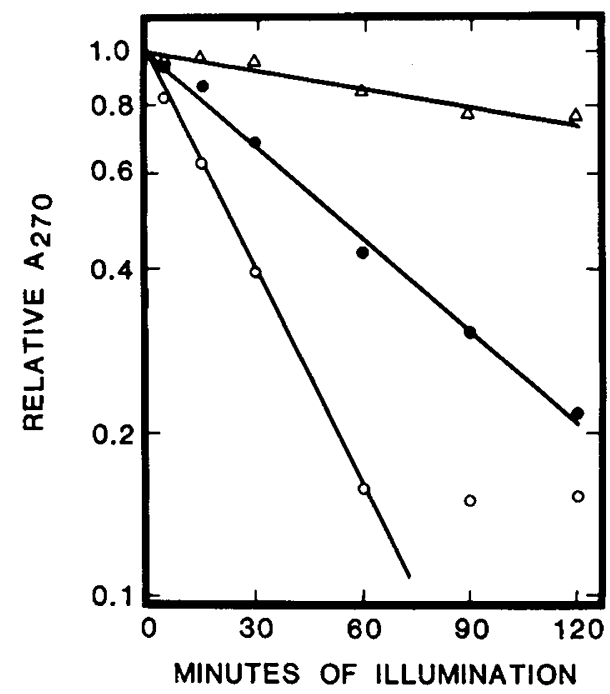

Fig. 3. Effect of a singlet oxygen promoter $\left(\mathrm{D}_{2} \mathrm{O}\right)$ and a singlet oxygen scavenger $\left(\mathrm{NaN}_{3}\right)$ on the rose bengal-induced photodecomposition of deoxyguanosine. All samples consisted of deoxyguanosine $(1 \mathrm{mg} / \mathrm{ml})$ plus $1.33 \times 10^{-4} \mathrm{M}$ rose bengal which were illuminated and diluted as described in "Materials and Methods." $\rightarrow$, samples in phosphate buffer; $\triangle$, samples in phosphate buffer plus $5 \mathrm{~mm}$ sodium azide; $O$, samples in phosphate buffer made with $\mathrm{D}_{2} \mathrm{O}$. Data presented as in Figure 2. The 90- and 120min data points for samples in $\mathrm{D}_{2} \mathrm{O}$ were not used in calculations of the least-squares best fit line.

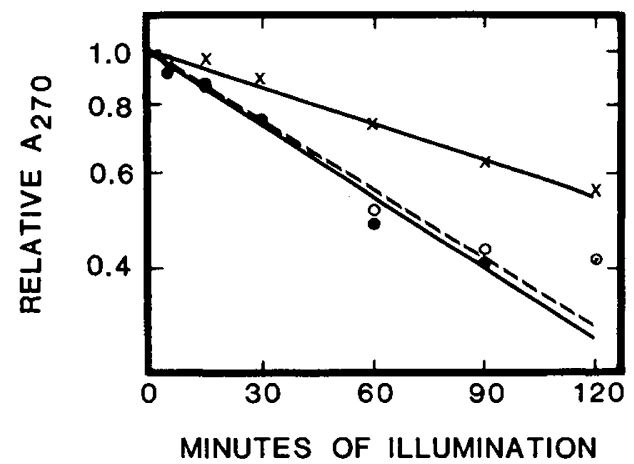

Fig. 4. Effect of $\mathrm{D}_{2} \mathrm{O}$ and $\mathrm{NaN}_{3}$ on the riboflavin-induced photodecomposition of deoxyguanosine. All samples consisted of deoxyguanosine (1 $\mathrm{mg} / \mathrm{ml}$ ) plus $1.33 \times 10^{-4} \mathrm{M}$ riboflavin which were illuminated and diluted as described in "Materials and Methods." $\times$, samples in phosphate buffer plus $5 \mathrm{~mm}$ sodium azide; $O$, samples in phosphate buffer made with $\mathrm{D}_{2} \mathrm{O}$. Data presented as in Figure 2. The 120min data points were not used in calculations the least-squares fits to the data in phosphate buffer and in $\mathrm{D}_{2} \mathrm{O}$. 


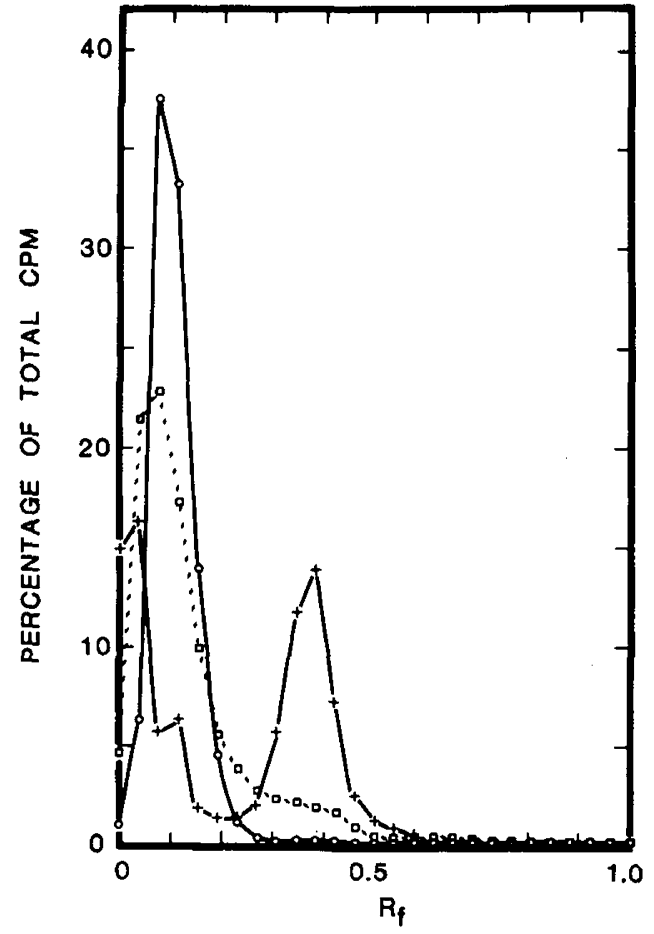

Fig. 5. Chromatographic patterns of photoproducts of deoxyguanosine produced by illumination in presence of either riboflavin or rose bengal. $O$, control, deoxyguanosine alone in the dark (total counts $=50,024$ ); $\square$, deoxyguanosine plus rose bengal $\left(1.33 \times 10^{-4} \mathrm{M}\right)$ illuminated for $60 \mathrm{~min}$ (total counts $=12,811) ;+$, deoxyguanosine plus riboflavin $\left(1.33 \times 10^{-4}\right.$ M) illuminated for $60 \mathrm{~min}$ (total counts $=25,166$ ). Chromatography was for $4 \mathrm{hr}$ in butanol:water $(86: 14 \mathrm{v} / \mathrm{v})$. See "Materials and Methods" for further experimental details.

sented in Figure 5, samples illuminated for both shorter and longer periods of time clearly showed different patterns for samples in rose bengal and samples in riboflavin. Chromatographic patterns were also different when butanol:water:concentrated ammonium hydroxide was used as the solvent system. The demonstration of different photoproducts in these two reactions provides additional support for different mechanisms of deoxyguanosine photodecomposition and suggests that the photodynamic reaction between riboflavin and deoxyguanosine is not mediated by singlet oxygen.

\section{DISCUSSION}

The interaction between visible light and riboflavin generates a highly reactive species of molecular oxygen, e.g., singlet oxygen. This molecule is capable of interacting with a number of substrates. Among the four deoxyribonucleosides in DNA, singlet oxygen specifically reacts with deoxyguanosine (4). Thus, it has been assumed that the photodynamic reaction of riboflavin and deoxyguanosine was dependent upon singlet oxygen (9).

The present study demonstrates that singlet oxygen does not participate in the riboflavin-induced photodecomposition of deoxyguanosine. Evidence for this is obtained from two observations: (1) the lack of an effect of the singlet oxygen promoter, deuterium oxide, on the kinetics of the photochemical reaction; and (2) a comparison of the photoproducts of the riboflavin photodynamic reaction with photoproducts derived from a known singlet oxygenmediated (rose bengal) decomposition of deoxyguanosine.

The exact nature of the photodynamic reaction between riboflavin and deoxyguanosine has not been determined. However, our observation that this reaction is efficiently quenched by sodium azide and not inhibited by catalase (7) suggests that an excited riboflavin molecule, possibly a riboflavin triplet, is involved in this reaction. Sodium azide has been shown to quench the triplet (excited) state of various dyes, including flavins (3). It is noteworthy that the primary reaction in the lumiflavin-sensitized oxidation of guanosine monophosphate is between the triplet state of lumiflavin and the nucleotide, which is followed by a later reaction involving ground-state oxygen (3). Further work to better define the photodynamic reaction of riboflavin and deoxyguanosine is necessary to prove a role for the riboflavin triplet in this photochemical reaction.

\section{REFERENCES AND NOTES}

1. Gromisch, D. S., Lopez, R., Cole, H. S., and Cooperman, J. M.: Light (phototherapy)-induced riboflavin deficiency in the neonate. J. Pediatr., 90: 118 (1977).

2. Hovi, L., Hekali, R., and Simes, M. A.: Evidence of riboflavin depletion in breast fed newborns and its further accleration during treatment of hyperbilirubinemia by phototherapy. Acta Paediatr. Scand., 68: 567 (1979).

3. Knowles, A., and Mautaer, G. N.: The flavin-sensitized photooxidation of nucleotides-III. The participation of oxygen. Photochem. Photobiol., 15: 199 (1972)

4. Loeber, G., and Kittler, L.: Selected topics in photochemistry of nucleic acids: Recent results and perspectives. Photochem. Photobiol., 25: 215 (1977).

5. Santella, R. M., Rosenkranz, H. S., Brem, S., Lubit, B. W., Erlanger, B. F., and Speck, W. T.: Peroxidase technique for the detection of photochemical lesions in intracellular deoxyribonucleic acid. Pediatr. Res., 11: 939 (1977).

6. Sisson, T. R. C., Salvin, B., and Hamilton, P. B.: The effect of broad and narrow spectrum fluorescent light on blood constituents. In: D. Bergsma, S. H. Blondheim: Bilirubin Metabolism in the Newborn. II. Excerpta Medica, Birth Defects-Original Article Series, Vol. 12, No. 2, pp. 122-133 (Elsevier-North Holland Publishing Co., New York, 1976).

7. Speck, W. T.: (unpublished results).

8. Speck, W. T., Chen, C. C., and Rosenkranz, H. S.: In vitro studies of effects of light and riboflavin on DNA and HeLa cells. Pediatr. Res., 9: 150 (1975).

9. Speck, W. T., Rosenkranz, S., and Rosenkranz, H. S.: Further observation on the photooxidation of DNA in the presence of riboflavin. Biochim. Biophys. Acta, 435: 39 (1976)

10. Tan, K. L., Chow, M. T., and Karim, S. M. M.: Effect of phototherapy on neonatal riboflavin status. J. Pediatr., 93: 494 (1978).

11. St. Louis, MO.

12. Pittsburg, PA.

13. Irvine, $\mathrm{CA}$.

14. Boston, MA.

15. Poole, England.

16. Corning Glass Works, Corning, NY.

17. Dr. W. T. Speck is a Research Career Development Awardee of the National Cancer Institute (1 K0-4-CA-00443).

18. The authors would like to acknowledge the assistance of Anne Vrana in the preparation of the manuscript.

19. Requests for reprints should be addressed to: W. T. Speck, M.D., Department of Pediatrics, Rainbow Babies and Childrens Hospital, Case Western Reserve University, 2101 Adelbert Road, Cleveland, OH 44106 (USA).

20. This research was supported by National Cancer Institute grant CA-23692-02.

21. Received for publication August 22, 1980.

22. Accepted for publication October 7, 1980. 